\title{
Practical Applications for Clinical Breast Examination (CBE) and Breast Self-Examination (BSE) in Screening and Early Detection of Breast Cancer*
}

\author{
Anthony B. Miller \\ Professor Emeritus, Department of Public Health Sciences, University of Toronto, Canada
}

\section{Key Words}

Breast cancer - Screening - breast examination, clinical . Breast self-examination

\section{Summary}

The background and preliminary results in terms of stage distribution are given for a trial of Clinical Breast Examination and the teaching of Breast Self-Examination in Cairo, Egypt. A stage shift towards early diagnosis appears to have been achieved. This has encouraged the development of similar projects in other middle income developing countries.

\section{Introduction}

The World Health Organization has adopted the following definitions [1]: An early detection program is the organized and systematic implementation of interventions that comprise early diagnosis, screening - if sufficient resources are available -, diagnosis, treatment and follow-up. Early diagnosis is the awareness (by the public or health professionals) of early signs and symptoms of cancer in order to facilitate diagnosis before the disease becomes advanced, thus enabling more effective and simpler therapy. This concept has been called by some 'downstaging'. Screening is the systematic application of a screening test in a presumably asymptomatic population in order to identify individuals with an abnormality suggestive of a specific cancer who then receive further investigation.

*Based upon a presentation made at the Global Summit on International Breast Health Care - Implementation, October 1-4, Budapest, Hungary.

\section{KARGER}

(C) 2008 S. Karger GmbH, Freiburg
Schlüsselwörter

Brustkrebs · Vorsorge - Brustuntersuchung, klinische . Brustselbstuntersuchung

\section{Zusammenfassung}

Dieser Artikel präsentiert den Hintergrund sowie vorläufige Ergebnisse zur Stadienverteilung einer Studie über die klinische Brustuntersuchung sowie die Lehre der Brustselbstuntersuchung in Kairo, Ägypten. Eine Stadienverschiebung zugunsten einer früheren Diagnose scheint erreicht worden zu sein, was zum Entstehen ähnlicher Projekte in anderen Entwicklungsländern mittleren Einkommens geführt hat.

Although the standard for screening for breast cancer in developed countries is mammography, most middle income and all low income developing countries can not afford mammography screening, because of the high cost of equipment, personnel and their training and films, so that in countries with breast cancer as an increasing problem, alternatives to mammography screening must be considered. These alternatives are: i) Early diagnosis through education - public, professional; ii) Good therapy; iii) Combination of above; iv) Screening clinical breast examination (CBE) and breast self-examination (BSE).

Health education should be the basis of all early detection programs. There is good evidence that in most developed countries the combination of professional and public education resulted in the reduction in the size of breast cancers on presentation, though in the absence of effective treatment, this appears to have had little impact upon mortality from breast cancer in these countries in the last decade. If mammography 
can not be afforded, an alternative is screening by allied health professionals using the combination of CBE and BSE. However, the evidence base in support of these screening tests is somewhat indirect. It largely comprises the first breast screening trial, set within the Health Insurance Plan of greater New York, which evaluated the combination of mammography as available in the 1970s and clinical breast examinations given by surgeons in which it was estimated that $70 \%$ of the effect was due to CBE [2] and the Canadian Breast Screening Study among women age 50-59 (CNBSS 2) [3]. In CNBSS 2, no benefit was found from adding mammography to CBE + BSE, while modeling indicated a probable $20 \%$ reduction in breast cancer mortality due to CBE + BSE [4]. Further, a nested case control study showed benefit from BSE among both women age 40-49 and 50-59 [5]. Another observational study (in Finland) also found a benefit from BSE [6]. 2 randomized trials have not reported any benefit from BSE, however. In one, in Shanghai, it already seemed that breast cancers were being diagnosed at a small size, and perhaps little could have been expected of BSE under those circumstances [7]. In the Russian trial, only the component where BSE was given on a background of annual CBEs has been reported, with some evidence that BSE was not practiced well [8].

It is important to recognize that a screening $\mathrm{CBE}$ is evaluating for signs of early breast cancer, minimal puckering of the skin, a small or indefinite lump; many of the signs of breast cancer usually taught indicate advanced disease. In the CNBSS, a very careful $\mathrm{CBE}$ was performed, generally by specially trained nurses: It has a visual component; Women are examined sitting up and lying down; All parts of the breast are examined; It takes 7-10 minutes; BSE is taught [9]. Teaching $\mathrm{BSE}$ is regarded as an integral part of the clinical breast examination. It may not be profitable to teach BSE by means of pamphlets, or used on its own as part of health education.

Breast screening should not be performed in the absence of adequate facilities for diagnosis, including: Fine needle aspiration cytology and/or excision biopsy (requiring the availability of a skilled (cyto)pathologist); ultrasound; mammography, if available, remembering mammography may be negative in a woman with breast cancer, especially if she is under the age of 50 .

\section{Results}

In the last few years, the application of these principles has been evaluated in the Cairo Breast Screening Trial [10]. This was coordinated from a community hospital, outside the center of Cairo, that served a population that could be readily identified. The process envisaged training social workers who visited homes in defined areas, and information was collected on women living in those homes, those age 40-69 being invited to attend a designated health center for examination by trained female doctors at special times. Any woman found to
Table 1. Preliminary comparison of stage distribution in the pilot study and the 2 subsequent study areas

\begin{tabular}{lcc}
\hline & Screen, \% & Control, \% \\
\hline Stage I & 30 & 8 \\
Stage II & 43 & 18 \\
Stage III & 20 & 44 \\
Stage IV & 7 & 30 \\
\hline
\end{tabular}

have an abnormality was invited to attend the community hospital for diagnosis, treatment being provided for those found to have breast cancer.

In the pilot, non-randomized part of the trial, 4,116 women were invited to attend the primary health center for examination, of which 2,481 (60\%) attended. Of those who attended, 291 were found to have abnormalities, and of them 236 (82\%) attended the community hospital for diagnosis. 20 women $(8 / 1,000)$ were diagnosed with breast cancer. In phase II of the pilot study, the women were separated into 2 groups by cluster randomization. In group $\mathrm{A}$, the active screening group, 1,924 women were invited to attend the health center for CBE, and $1,602(83 \%)$ attended. Of these, 63 were found to have abnormalities, and $52(83 \%)$ attended the community hospital for diagnosis. 3 women $(1.8 / 1,000)$ were diagnosed with breast cancer. The women in Group B comprised the controls who received only health education. They were visited 1 year later than women in group A were screened. 1,924 women were contacted by the social workers, and 7 were identified who had developed breast cancer in the 2 years since Phase I (1.8/1,000/year). In subsequent phases of the trial, 2 additional areas were identified, accessible to the headquarters community hospital, each with approximately 5,000 women age 50-64, who were cluster randomized from the time of their identification to a screened group and a health education only control group. The reputation of the trial preceded subject recruitment, and there was high community acceptance, with $85-91 \%$ of the women accepting invitations to attend a designated primary health center for CBE screening and the teaching of BSE. The detection rate on first screening was 5/1,000, and on re-screening 3/1,000. Although follow-up of all groups is yet to be completed, a preliminary comparison of stage distribution in the pilot study and the 2 subsequent study areas is presented in table 1. Further information on the methodology and scientific basis of the trial, and other trial centers, can be obtained from the author.

\section{Discussion}

The preliminary findings from this trial are encouraging. However, until the follow-up is complete, we shall not be certain that a major stage shift has been achieved. It is likely that women with previously undetected breast cancer in both groups are likely to be more advanced, so the favorable stage distribution in the screened group may be more optimistic 
than reality. Nevertheless, we anticipate that there will be fewer 'missed' cancers in the screened group than the control, so the favorable stage distribution screen vs. control group is unlikely to disappear when the follow-up data are fully available. However, it is possible to have improvements in stage without consequent reduction in breast cancer mortality (that was seen in the CNBSS, comparing the mammography screened groups with the control groups). This is largely an effect of lead time and over-diagnosis. With CBE screening the lead time is less, and over-diagnosis much less than with mammography.

No project can be run in any country without encountering some problems. So far, it has not been possible to obtain funding for expansion of the project to other areas of Egypt. Further, with a change in the Minister of Health it has been difficult to maintain support of the government, though as the President's wife agreed to sponsor the project, and with it not depending on government funding, it has continued. More difficult has been conflicting advice from other Western Groups, especially regarding mammography. A visit to Egypt by representatives of a non-government organization from a European country persuaded the new Minister of Health (a radiologist) that a mammography screening program was feasible for Egypt, using mobile vans equipped with mammography machines. Time will tell whether it is possible to organize such a program. Finally, there have been difficulties in ensuring follow-up, especially of control groups and non-responders, but we are hoping to overcome this in the next year.

Building on the experience in Cairo, other pilot projects have been initiated in 4 other countries in the Eastern Mediterranean Region. In 2006, using essentially the same protocol, projects were initiated in Sana'a, Yemen and Khartoum, Sudan. In 2007, it was agreed that a project should be initiated in Erbil, Iraq, and Yazd, Iran. The Yazd project began recently. The Sana'a project uses individual randomization, the others cluster randomization, as in Cairo. It is too early to know whether these projects will encounter similar problems to the Cairo project.

There have been other trials of CBE - a trial in the Philippines supported by the International Agency for Research on Cancer was abandoned, because only a small proportion of the women found to have abnormalities on CBE agreed to attend hospital for investigation [11]. This was a problem in Cairo, though with appropriate health education, it was overcome. It was also not a major problem in a major trial of $\mathrm{CBE}$ combined with visual inspection of the cervix in Mumbai India, initial reports on this trial are expected soon.

Improving the stage distribution (downstaging) of cases that present clinically has been demonstrated in a pilot project over 4 years in Sarawak, Malaysia [12]. This project consisted of training health staff in hospital and rural clinics to improve their skills in early cancer detection, and raising public awareness through pamphlets, posters, and sensitization by health staff. The Cairo project suggests that additional benefit will be obtainable by a program of $\mathrm{CBE}+\mathrm{BSE}$ screening, but it remains to be seen whether this is cost-effective.

Given the present level of evidence, countries contemplating the introduction of new or re-organization of existing screening programs should first ensure that health education for women, and professional education of primary care practitioners to enable them to recognize the signs of early breast cancer, is in place. The program should encourage early diagnosis of breast cancer, especially for women aged 40-69 years who are attending primary health care centers or hospitals for other reasons, by offering clinical breast examinations to those concerned about their breasts and promoting awareness in the community. If mammography is available, the top priority is to use it for diagnosis, especially for women who have detected an abnormality by self-examination. It should be borne in mind, however, that cancer may be present even if the mammogram is negative. Mammography should not be introduced for screening unless the resources are available to ensure effective and reliable screening of at least $70 \%$ of the priority target age group, that is, women over the age of 50 years. Screening by BSE and CBE could be contemplated in demonstration projects similar to that in Cairo, pending the acquisition of further evidence.

In determining the relative priorities for different screening programs, it is important to recognize that breast cancer screening is intrinsically less effective than cytological screening for cervical cancer. As a rough guide, screening will produce an equivalent reduction in numbers of deaths in the 2 conditions only if, in the absence of screening, breast cancer mortality is 3 times that of cervical cancer in the age groups concerned. In conclusion, the Cairo Breast Screening trial has demonstrated that it is possible to screen women in an urban area with $\mathrm{CBE}$, and teach them BSE, and preliminary results suggest that a stage shift has been achieved. It is too early, however, and the numbers studied are too few, to know whether such screening will reduce breast cancer mortality.

\section{Acknowledgements}

I express my grateful thanks to the investigators of the Cairo Breast Screening Trial, Salwa Boulos (Principal Investigator), Moysen Gadallah (Statistician), Sherif Neguib (Surgeon), EA Essam (Pathologist), and A Youssef (Medical Oncologist), and those investigators in other countries who are gearing up to collaborate in a multi-country investigation. 


\section{References}

1 World Health Organization: Cancer Control. Knowledge into Action. WHO Guide for Effective Programs. Module 3: Early Detection. Geneva, World Health Organization, 2007.

2 Shapiro, S, Strax P, Venet L, Venet W: Periodic Screening for Breast Cancer. The Health Insurance Plan Project and its Sequelae, 1963-1986. Balti more, The Johns Hopkins University Press, 1988

3 Miller AB, To T, Baines CJ, Wall C: Canadian National Breast Screening Study - 2: 13-year results of a randomized trial in women aged 50-59 years. J Natl Cancer Inst 2000;92:1490-1409.

4 Rijnsburger AI, van Oortmarssen GJ, Boer R, Draisma G, To T, Miller AB, de Koning HJ: Mammography benefit in the Canadian National Breast Screening Study - 2: a model evaluation. Int J Cancer 2004; 110: 756-762.

5 Harvey BJ, Miller AB, Baines CJ, Corey PN: Effect of breast self-examination techniques on the risk of death from breast cancer. Can Med Assoc J 1997; 157:1205-1212.
6 Gastrin G, Miller AB, To T, Aronson KJ, Wall C, Hakama M, Louivouri K, Pukkala E: Incidence and mortality from breast cancer in the Mama program for breast screening in Finland, 1973-1986. Cancer 1994; 73:2168-2174.

7 Thomas DB, Gao DL, Ray RM, Wang WW, Allison CJ, Chen FL, Porter P, Hu YW, Zhao GL, Pan LD, Li W, Wu C, Coriaty Z, Evans I, Lin MG, Stalsberg $\mathrm{H}$, Self SG: Randomized trial of breast self-examination in Shanghai: final results. J Natl Cancer Inst 2002;94:1445-1457.

8 Semiglasov VF, Moiseyenko VM, Manikhas AG, Protsenko SA, Kharikova RS, Ivanov VG, Baresh NJ, Seleznev IK, Migmanova NSh, Ivanova OA, Orlov AA, Popova RT, Chagunava OL: Role of breast self-examination in early detection of breast cancer: Russia/WHO prospective randomized trial in St. Petersburg. Cancer Strategy 1999;1:145-151.
9 Bassett AA: Physical examination of the breast and breast self-examination; in Miller AB (ed): Screening for Cancer. Orlando, Academic Press Inc, 1985, pp. 271-291.

10 Boulos S, Gadallah M, Neguib S, Essam Ea, Youssef A, Costa A, Mittra I, Miller AB: Breast screening in the emerging world: high prevalence of breast cancer in Cairo. Breast 2005;14:340-346.

11 Pisani P, Parkin DM, Ngelangel C, Esteban D, Gibson L, Munson M, Reyes MG, Laudico A: Outcome of screening by clinical examination of the breast in a trial in the Philippines. Int J Cancer 2006;118: 149-154.

12 Devi BCR, Tang TS, Corbex M: Reducing by half the percentage of late-stage presentation for breast and cervix cancer over four years: a pilot study of clinical downstaging in Sarawak, Malaysia. Ann Oncol 2007;18:1172-1176. 